\title{
Correlation of imaging data and intraoperative data of vascular abnormalities during kidney transplantation
}

\author{
O.ELIDRISSI,Y.FADIL,Y.GHANNAM,M.DAKIR,A.DEBBAGH,R.ABOUTAIEB
}

\author{
Departement of Urology, Ibn rochd university hospital center,Casablanca
}

\begin{abstract}
ORenal transplantation from a living related donor represents an alternative for patients with end-stage chronic kidney disease. This requires a precise preoperative assessment of the donor in order to determine the side of the kidney to be removed according to the anatomical conditions, in particular the renal vascularization.
\end{abstract}

The presence of vascular anomalies within the couple poses a real problem at several stages:

- Donor selection stage.

- Choice of side to be withdrawn.

- Surgical step during kidney removal and transplantation with greater operational risks compared to a donor without vascular abnormalities, which may compromise the future of the transplant.

The objective of our work is to correlate the results of imaging, which allows the diagnosis of vascular abnormalities in renal transplantation from living related donors, and the surgical data.

This is a retrospective study, carried out on 259 living related donors, extended over a period of 8 years, concerning renal transplants from living related donors (DVA) performed at the Ibn Rochd University Hospital in Casablanca.

We report a series of 22 couples presenting vascular anomalies of different types found during the renal transplant process during the radiological assessment or during the operation, as well as the sensitivity of the imaging means to detect the various vascular anomalies.

Renal transplantation with vascular anomaly requires surgical expertise, both during the harvest and during the renal transplant, as well as collaboration between the various stakeholders "surgeons, radiologists, nephrologists and anesthetists" for the success of the transplant.

Goal: To assess the prevalence of vascular abnormalities in kidney transplantation from living related donors, the imaging means that allow their diagnosis, and the correlation between the imaging results and the intraoperative data.

\section{Introduction}

The presence of vascular abnormalities within the couple during kidney transplantation poses a real problem at several stages:

- Donor selection stage.

- Choice of side to be withdrawn.

- Surgical step during kidney removal and transplantation with greater operational risks compared to a donor without vascular abnormalities, which may compromise the future of the transplant.

We report a series of 22 couples with vascular abnormalities found during the renal transplant process performed in the urology department at Ibn Rochd University Hospital over a period of 8 years.

\section{RESULTS}

On angiography scanner 27 vascular anomalies were found, 20 arterial anomalies including 13 of number ( 9 double arteries, 2 triple arteries, 2 accessory polar arteries) and 7 of morphologies ( 7 early arterial bifurcations) and 7 venous including 2 supernumerary veins (2 double renal veins), 3 situations ( 2 retro aortic veins and a left inferior vena cava) and 2 morphology (a bifid renal vein and an early vein bifurcation).

Two patients were rejected for vascular abnormalities seen on CT angiography. The left side was chosen for sampling in 15 patients, and the right side

in 5 patients. Among these 20 living donors, the sample 
was taken from the side of the vascular abnormality in 8 cases.

During the operation, there are 25 vascular anomalies, 13

Table 1: Vascular abnormalities found intraoperatively

\begin{tabular}{|c|c|c|}
\hline Anomaly & Percentage & Number of cases \\
\hline Early arterial bifurcation & $24 \%$ & 6 cases \\
\hline Double kidney vein & $16 \%$ & 4 cases \\
\hline Short renal vein & $12 \%$ & 3 cases \\
\hline Double artery & $8 \%$ & 2 cases \\
\hline Triple artery & $8 \%$ & 2 cases \\
\hline Superior polar artery & $4 \%$ & 1 cases \\
\hline Small artery & $8 \%$ & 2 cases \\
\hline Left VCI & $4 \%$ & 1 cases \\
\hline Retro aortic vein & $4 \%$ & 1 cases \\
\hline Bifid renal vein & $8 \%$ & 2 cases \\
\hline Early venous bifurcation & $4 \%$ & 1 cases \\
\hline
\end{tabular}

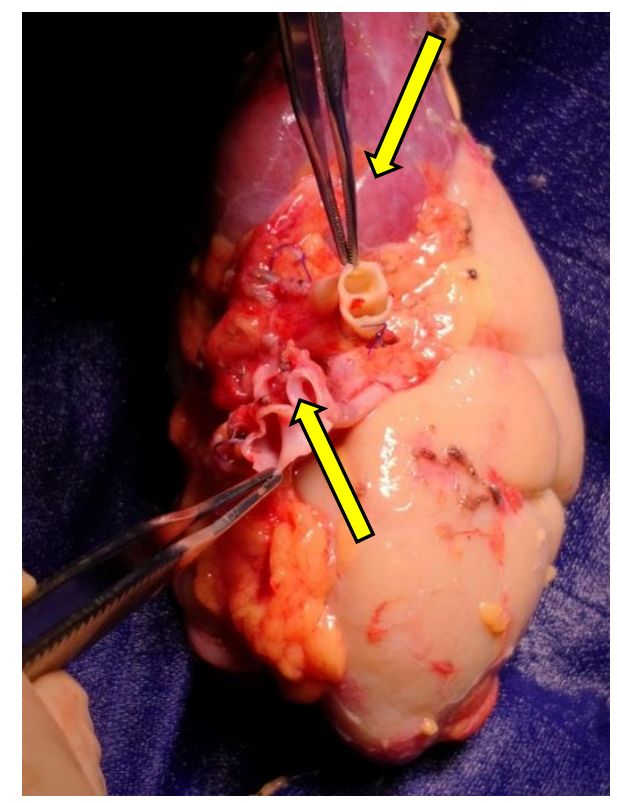

Figure 1: Early bifurcation of the renal artery and vein 


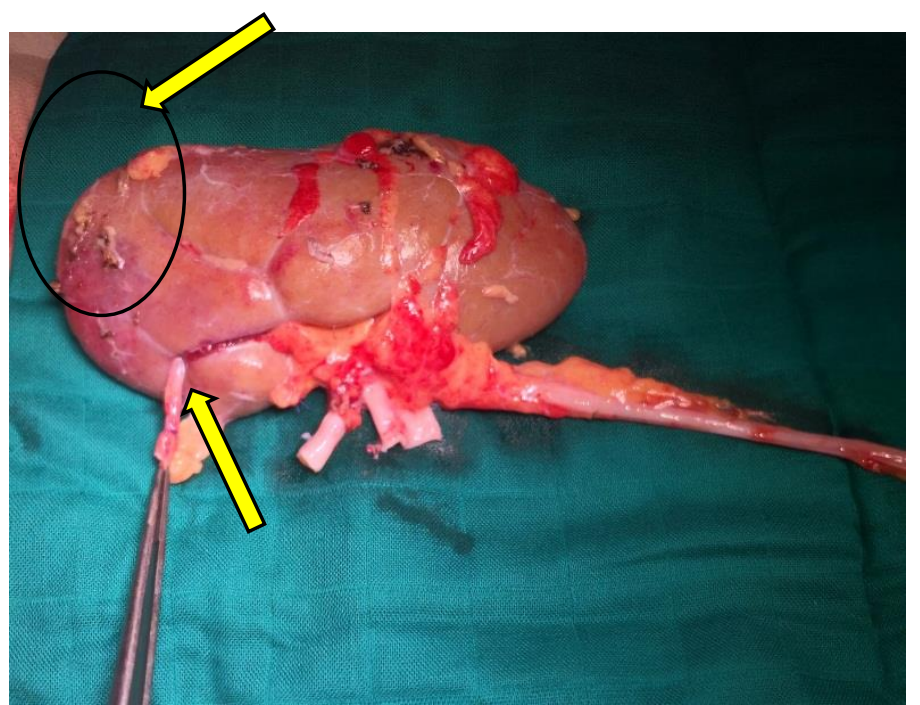

Figure 2: Ligated superior polar artery with ischemia zone $<30 \%$

Table 2: Correlation of vascular abnormalities between CT angiography data and surgical results

\begin{tabular}{|c|c|c|c|}
\hline & Side CT & CT angiography result & Intraoperative result \\
\hline Giver 1 & Left & Retro aortic renal vein & Retro aortic renal vein \\
\hline Giver 2 & Left & Early arterial bifurcation & Early arterial bifurcation \\
\hline Giver 3 & Right & Early arterial bifurcation & Early arterial bifurcation \\
\hline Giver 4 & Left & Early bifurcation + bifid renal vein & Early bifurcation + bifid renal vein \\
\hline Giver 5 & Right & Double renal artery & Double renal artery \\
\hline Giver 6 & Left & Single artery and vein of normal morphology & Single artery and vein of normal morphology \\
\hline Giver 7 & Right & Single artery and vein of normal morphology & Single artery and vein of normal morphology \\
\hline Giver 8 & Left & Superior polar artery & Superior polar artery \\
\hline Giver 9 & Left & Left IVC & Double renal artery + left IVC \\
\hline Giver 10 & Left & Single artery and vein of normal morphology & Early left arterial bifurcation \\
\hline Giver 11 & Right & $\begin{array}{l}\text { Main trunk }(\mathrm{L}=35 \mathrm{~mm} ; \mathrm{D}=6 \mathrm{~mm})+\text { small spindly } \\
\text { artery } \\
\text { upper polar accessory of the same trunk as the adre- } \\
\text { nal artery }\end{array}$ & Triple renal artery of which 2 are hailstones \\
\hline Giver 12 & Left & $\begin{array}{l}\text { Early bifurcation of the left renal artery associated } \\
\text { with an accessory polar artery }\end{array}$ & Triple renal artery \\
\hline Giver 13 & Left & Unique renal artery and vein of normal morphology & Double renal vein \\
\hline Giver 14 & Left & Unique renal artery and vein of normal morphology & Double renal vein \\
\hline Giver 15 & Left & Unique renal artery and vein of normal morphology & Double renal vein \\
\hline Giver 16 & Right & Unique renal artery and vein of normal morphology & Short renal vein \\
\hline Giver 17 & Right & Unique renal artery and vein of normal morphology & Double renal vein + vein short renal \\
\hline Giver 18 & Left & Early arterial bifurcation & Early arterial bifurcation + short renal vein \\
\hline Giver 19 & Left & Unique renal artery and vein of normal morphology & Small artery + early venous bifurcation \\
\hline Giver 20 & Left & $\begin{array}{l}\text { Early arterial bifurcation and single renal vein of } \\
\text { normal morphology }\end{array}$ & $\begin{array}{l}\text { Early arterial bifurcation and bifidity of the } \\
\text { renal vein }\end{array}$ \\
\hline
\end{tabular}

\section{DISCUSSION}

Frequency of vascular abnormalities: The overall frequency of vascular abnormalities is very diverse from one study to another. In the study by Singh and AL [1], the overall frequency was $28 \%$ for 36 living related donors, of whom 10 had vascular abnormalities.

Lim and AL [2] found an overall frequency of $17 \%$ for 109
DVA, of which 19 presented vascular anomalies.

In our study the overall frequency was $8.5 \%$.

Diagnostic method: The Angioscanner is the Gold standard for the preoperative work-up, which allows a good understanding of the vascular anatomy of the graft. [3], [4]

We notice a sensitivity of $100 \%$ for Turkvatan and al. [5] 
for major arterial and venous abnormalities and less sensitivity for minor venous abnormalities amounting to $79 \%$. Rashid and al [6] also reported in their study a sensitivity of $100 \%$ all anomalies combined.

Tombul and al [7] found in his study that CT angiography has a sensitivity of around $95 \%$ for the detection of arterial anomalies and $93 \%$ for venous anomalies.

Angio MRI is not the gold standard in the pre-transplant workup, but can replace angiography as a safe and accurate modality for the evaluation of the vascular anatomy of potential living donors.

\section{Correlation between radiological data and surgical} data:The study by Turkvatan and al. [5] found a correlation rate between radiological and surgical data of $100 \%$.

In the Platt and al. [8] study, we noticed a correlation rate between radiological and surgical data of $95 \%$ with 5 cases of accessory renal arteries (less than $2 \mathrm{~mm}$ in diameter) and one case of early arterial bifurcation not seen on CT angiography.

In the literature, several authors have discussed that a weak correlation is sometimes found between radiological and surgical data when trying to point the finger at these reasons:

- Poor CT Angiography in detecting small caliber accessory branches.

- The lack of rereading of the CT images exposing the risk of overriding an anomaly, hence the interest of collaboration between radiologists for a possible rereading.

- And finally the lack of codification of the procedure for evaluating renal anatomy where the sections must be thin enough to detect certain abnormalities.

\section{Anomalies discovered during the operation:}

Arterial Anomalies of Number: We notice a low rate of multiple renal arteries of all types compared to the literature, this is due to the choice of the opposite side in most patients in whom we have found an anomaly of number and this in order to improve the prognosis of the graft. Note that for the study by Platt and al. [8] 5 accessory arteries were not seen underlining the difficulty that CT Angiography finds in visualizing them.

Marcel and al [9] have demonstrated that grafts with multiple renal artery were associated with a higher risk of complication, but had comparable long-term outcomes in terms of graft and patient survival rates. For this reason, the presence of MRA should be a contributing factor in the decision regarding which kidney is best for donation.

It is the most frequently found anatomical variant with a prevalence of $32.4 \%$ of a double renal artery, and $5 \%$ of a triple renal artery. [10]
Arterial Anomalies of Morphology: The rate of early bifurcations of the renal arteries found during the operation in our series is similar to those found in the literature.

The results obtained on CT angiography and those reported in the intraoperative phase are consistent, thus denoting the sensitivity of CT angiography to early arterial bifurcations.

Venous Number Anomalies: We notice a discrepancy between the results of the CT angiography and the surgical data, which was confirmed by our study as well as the data in the literature, which is the studies of Raman and al [11], Rashid and al [6] and Platt and al [8].

Venous Anomalies of Morphology: In the literature, we find in Platt and $\mathrm{Al}$ [8] and Turkvatan [5] and al early venous bifurcation at the respective rates of $3.7 \%$ and $14.28 \%$. In our study 2 cases of venous morphological abnormalities "An early bifurcation and a bifid renal vein" were found intraoperatively and not seen on CT angiography.

\section{Conclusion}

Now kidney transplantation is increasingly recognized as the first choice therapeutic alternative for chronic renal failure, so surgical expertise in harvesting and transplantation is required for comparable results in the absence of vascular abnormalities.

\section{References}

1. Singh, P. B., Goyal, N. K., Kumar, A., Dwivedi, U. S., Trivedi, S., Singh, D. K., \& Prakash, J. (2008). Renal transplantation using live donors with vascular anomalies: a salvageable surgical challenge. Saudi Journal of Kidney Diseases and Transplantation, 19(4), 554.

2. Lim, Y. M. J., Han, X., Raman, L., Ng, T. K., Goh, T. H. A., Vathsala, A., \& Tiong, H. Y. (2016, April). Outcome of living donor transplant kidneys with multiple arteries. In Transplantation Proceedings (Vol. 48, No. 3, pp. 848-851). Elsevier.

3. Bouali, O., Mouttalib, S., Labarre, D., Munzer, C., Lopez, R., Lauwers, F., \& Moscovici, J. (2014). Radiological study of the anatomical variations of the renal veins by multidetector CT scan in thin sections. Morphology, 98 (323), 161-165.

4. Namasivayam, S., Small, W. C., Kalra, M. K., Torres, W. E., Newell, K. A., \& Mittal, P. K. (2006). Multidetector-row CT angiography for preoperative evaluation of potential laparoscopic renal donors: how accurate are we? Clinical imaging, 30(2), 120-126.

5. Türkvatan, A., Akıncı, S., Yıldız, Ş., Ölçer, T., \& Cumhur, T. (2009). Multidetector computed tomography for preoperative evaluation of vascular anatomy in living renal donors. Surgical and radiologic anatomy, 31(4), 227-235.

6. Rashid, R. J., Tarzemani, M. K., Mohtasham, M. A., Zomorrodi, A., Kakaei, F., Jalili, J., \& Habibzadeh, A. (2014). Diagnostic accuracy of 64MDCT angiography in the preoperative evaluation of renal vessels and compared with laparotomy findings in living donor kidney. Renal Failure, 36(3), 327-331.

7. Tombul, S. T., Aki, F. T., Gunay, M., Inci, K., Hazirolan, T. U. N. C. A. Y., Karcaaltincaba, M. U. S. T. U. R. A. Y., ... \& Bakkaloglu, M. (2008, January). Preoperative evaluation of hilar vessel anatomy with 3-D computerized tomography in living kidney donors. In Transplantation proceedings (Vol. 40, No. 1, pp. 47-49). Elsevier.

8. Platt, J. F., Ellis, J. H., Korobkin, M., \& Reige, K. (1997). Helical CT evaluation of potential kidney donors: findings in 154 subjects. AJR. American journal of roentgenology, 169(5), 1325-1330. 
9. Zorgdrager, M., Krikke, C., Hofker, S. H., Leuvenink, H. G., \& Pol, R. A. (2016). Multiple renal arteries in kidney transplantation: a systematic review and meta-analysis. Ann Transplant, 21(469), 10-12659.

10. Costa, A., Matter, M., Pascual, M., Doerfler, A., \& Venetz, J. P. (2019). Renal, vascular and urological variations and abnormalities in living kidney donor candidates. Progres en urologie: journal de l'Association francaise d'urologie et de la Societe francaise d'urologie, 29(3), 166.
11. Raman, S. S., Pojchamarnwiputh, S., Muangsomboon, K., Schulam, P. G., Gritsch, H. A., \& Lu, D. S. (2006). Utility of 16-MDCT angiography for comprehensive preoperative vascular evaluation of laparoscopic renal donors. American Journal of Roentgenology, 186(6), 1630-1638.

Citation: 0.ELIDRISSI,Y.FADIL,Y.GHANNAM,M.DAKIR,A.DEBBAGH,R.ABOUTAIEB, "Correlation of imaging data and intraoperative data of vascular abnormalities during kidney transplantation". American Research Journal of Urology, vol 4, no. 1, 2020, pp. 1-5.

Copyright (c) 2020 Elidrissi Alami Oussama, et al. This is an open access article distributed under the Creative Commons Attribution License, which permits unrestricted use, distribution, and reproduction in any medium, provided the original work is properly cited. 